\title{
PENINGKATAN KESEHATAN MASYARAKAT SELAMA PANDEMI DALAM UPAYA PENCEGAHAN LOW BACK PAIN
}

\author{
Tjie Haming Setiadi ${ }^{1}$, Alexander Halim Santoso ${ }^{2}$, David Limanan ${ }^{3}$, Erick Sidarta ${ }^{4}$ dan \\ Susy Olivia Lontoh ${ }^{5}$
}

\author{
${ }^{1}$ Bagian Anatomi, Fakultas Kedokteran, Universitas Tarumanagara Jakarta \\ Email: tjies@fk.untar.ac.id \\ ${ }^{2}$ Bagian Ilmu Gizi, Fakultas Kedokteran, Universitas Tarumanagara Jakarta \\ Email: alexanders@fk.untar.ac.id \\ ${ }^{3}$ Bagian Biokimia, Fakultas Kedokteran, Universitas Tarumanagara Jakarta \\ Email: davidl@fk.untar.ac.id \\ ${ }^{4}$ Bagian Histologi, Fakultas Kedokteran Universitas Tarumanagara Jakarta \\ Email: ericksi@fk.untar.ac.id \\ ${ }^{5}$ Bagian Fisiologi, Fakultas Kedokteran, Universitas Tarumanagara Jakarta \\ Email: susyo@fk.untar.ac.id
}

\begin{abstract}
The global pandemic has made most of the activities at home. This condition poses significant health challenges. The increasing number of hours spent sitting, having improper posture, lack of exercise, unhealthy diet and pandemic stress can all lead to the low back pain. Low Back Pain is a multifactorial disease. Therefore, an integrated prevention strategy is needed to prevent Low Back Pain. Based on these problems, the community service activity was held. This activity is carried out to provide education related to knowledge of back pain in good working positions, movements to avoid, and exercises that can overcome complaints of back pain. The target of this activity is to increase public knowledge regarding low back pain, improve individual health degrees, educate healthy lifestyles, pay attention to nutritional intake, be active in sports, reduce the incidence of back pain and improve quality of life so that they can continue to work during the pandemic. This activity was carried out online on 27 May 2021 at 8.00-12.00 and was attended by 44 participants from PKK cadres, Tomang Village, West Jakarta. In addition, pre-test and post-test were also conducted. The average score of the pre-test was 53.63, while the average score of the post-test was 62.27. These results indicate that there is an increase in knowledge of $16.10 \%$. Participants are expected to be able to apply the knowledge related to preventing back pain with exercise, good nutrition and can educate families about habits in preventing back pain.
\end{abstract}

Keywords: Pandemic, Low Back Pain

\begin{abstract}
ABSTRAK
Pandemi global telah membuat sebagian besar beraktivitas di rumah. Kondisi ini menimbulkan tantangan kesehatan yang signifikan. Meningkatnya jumlah jam yang dihabiskan untuk duduk, memiliki postur tubuh yang tidak tepat, kurang olah raga, pola makan yang tidak sehat dan stres pandemi dapat menyebabkan nyeri punggung bawah yang berkepanjangan. Low Back Pain merupakan penyakit multifaktor. Oleh karena itu, perlu strategi pencegahan terpadu untuk mencegah Low Back Pain. Berdasarkan permasalahan tersebut, kegiatan penyuluhan terkait nyeri pinggang belakang dan bagaimana mengatasinya diselenggarakan. Kegiatan ini dilakukan untuk memberikan edukasi terkait pengetahuan nyeri pinggang belakang posisi kerja yang baik, gerakan yang dihindari, serta senam yang dapat mengatasi keluhan nyeri pinggang belakang. Target kegiatan ini adalah bertambahnya pengetahuan masyarakat terkait low back pain, meningkatkan derajat kesehatan individu, mengedukasi pola hidup sehat, memperhatikan asupan gizi, giat berolahraga, menurunkan angka kejadian nyeri pinggang belakang serta meningkatkan kualitas hidup agar tetap berkarya selama pandemi. Kegiatan ini dilakukan via daring pada tanggal 27 Mei 2021 pukul 8.00-12.00 dan dihadiri oleh 44 peserta yang berasal dari kader PKK Kelurahan Tomang Jakarta Barat. Selain itu, juga dilakukan pre-test dan post-test. Nilai rata-rata pre-test adalah 53.63, sedangkan nilai rata-rata pos-test adalah 62.27. Hasil tersebut menunjukan bahwa terjadi peningkatan pengetahuan sebesar $16.10 \%$. Para peserta diharapkan dapat menerapkan materi terkait pencegahan nyeri pinggang belakang dengan senam, asupan gizi yang baik dan dapat mengedukasi keluarga tentang kebiasaan dalam mencegah nyeri pinggang belakang.
\end{abstract}

Kata kunci: Pandemi, Nyeri Pinggang Belakang

\section{PENDAHULUAN}

Saat ini, masalah yang berhubungan dengan nyeri punggung bawah atau Low Back Pain (LBP) merupakan perhatian utama masyarakat, otoritas kesehatan, serta untuk populasi umum di negara 
maju (James et al., 2017). Di seluruh dunia diperkirakan bahwa prevalensi LBP berkisar antara 1,4 sampai 20,0\% (Fatoye et al., 2019). Faktanya, LBP adalah penyebab umum yang paling banyak membuat gangguan muskuloskeletal yang berhubungan dengan pekerjaan di daerah tertentu dan juga penyebabnya masalah signifikan baik dalam kehidupan pribadi maupun profesional individu (Meisha et al., 2019). Low Back Pain dapat menyebabkan gangguan tidur, kecacatan, kurangnya produktivitas kerja dan kesulitan dalam melaksanakan kegiatan sehari-hari serta keterbatasan dalam melaksanakan profesi pekerjaan (Simsek at el., 2017).

LBP juga memberi dampak besar pada ekonomi seluruh dunia, di negara Barat diperkirakan bahwa biaya nyeri punggung berkisar antara 1 dan 2\% dari produk nasional bruto (Dutmer et al., 2019). Di Amerika Serikat, para ahli telah menghitung biaya total kondisi akibat LBP melebihi \$ 100 miliar per tahun (Crow \& Willis, 2003). Center for Control and Prevention (CDC) dalam the American Academy of Pain Medicine (2008) menyatakan bahwa 100 juta orang dewasa di Amerika Serikat melaporkan keluhan nyeri pinggang belakang sebanyak 28,1\% (Gallagher, 2008). Angka kejadian keluhan nyeri pinggang belakang merupakan 1 dari 10 penyakit terbanyak di Amerika Serikat dan eringkat ke 5 dalam daftar penyebab seorang pasien berobat ke dokter (Minghelli, 2017)

Low Back Pain sering dikaitkan dengan penerapan atau penempatan postur tubuh yang buruk di kegiatan sehari-hari atau tempat kerja seperti angkat berat yang berlebihan, melakukan gerakan berulang seperti fleksi batang, rotasi, dan hiperekstensi; mendorong; menarik;membawa; getaran seluruh tubuh (Coenen, 2013). Selain itu, faktor resiko tertentu dapat memperburuk intensitas Low Back Pain yaitu usia, jenis kelamin, hipertensi, merokok, ergonomi, kurangnya kepuasan kerja, kelebihan berat badan atau obesitas, kurangnya aktivitas fisik dan depresi (Brady et al., 2016; Bento et al., 2020).

Pada situasi saat ini timbulnya pandemik akibat penyakit coronavirus 2019 (COVID-19), telah memaksa banyak pemerintah di seluruh dunia untuk membuat serangkaian keputusan untuk mencegah cepatnya pandemi menyebar (Huang et al., 2020). Tindakan pencegahan yang diterapkan meliputi jarak sosial, pembatasan kapasitas di ruang publik dan rumah pribadi, isolasi, karantina, dan penegakan jam malam (Wilder-Smith et al., 2020) . Oleh karena itu dapat dibayangkan bahwa semua peristiwa ini kemungkinan besar telah memengaruhi kehidupan orangorang secara fisik, emosional, dan secara psikologis. Mattioli et al. (2020) menyatakan bahwa tindakan karantina berdampak negatif berdampak pada manusia dalam banyak aspek, yang meliputi (a) peningkatan kecemasan, kemarahan, dan stres; (b) penurunan aktivitas fisik serta latihan di luar ruangan dan semua kegiatan dilakukan di dalam rumah atau ruangan (c) stres dan depresi, yang mana bisa mengarahkan individu untuk melakukan kebiasaan diet yang tidak sehat. Keluhan nyeri pinggang belakang atau low back pain merupakan keadaan tidak spesifik yang terhadap individu, nyeri pinggang belakang dapat nyeri yang akut atau kronik dan memberikan rasa tidaknyamanan pada atau di dekat daerah lumbosacral.

Nyeri pinggang belakang dapat disebabkan oleh trauma, inflamasi, proses degeneratif, keganasan, kelainan ginekologi dan gangguan metabolik. (Emel \& Ozden, 2012). Keluhan nyeri pinggang belakang dapat hubungkan dengan faktor risiko yaitu faktor individu (genetik, jemis kelamin, usia, IMT, masa kerja, lama kerja, minum kafein, kebiasaan merokok, riwayat pendidikan, kesegaran jasmani, riwayat terkait penyakit rangka dan riwayat trauma) (Lionel, 2014; Alhalabi et al., 2015). Faktor lain yang dapat menimbulkan keluhan nyeri pinggang belakang adalah berhubungan dengan pekerjaan seperti posisi kerja, beban kerja, repetisi dan durasi, sikap duduk yang tidak tepat, postur tubuh yang tidak ideal, serta lingkungan fisik. (Almoallim et al., 2014) 
Seseorang saat sedang melakukan pekerjaannya dapat merasakan nyeri pinggang belakang, tetapi duduk lama dalam posisi statis mempunyai risiko lebih besar untuk mengalami nyeri pinggang belakang. Duduk lama dalam posisi statis menyebabkan otot berkontraksi terus menerus dan pembuluh darah menyempit. Pembuluh darah yang menyempit menyebabkan aliran darah terhambat akibatnya iskemia, asupan nutrisi dan oksigenisasi ke jaringan berkurang, sedangkan kontraksi otot yang lama membutuhkan aliran darah yang baik. Keadaan ini menyebabkan kadar asam laktat meningkat dan timbul rasa nyeri. (Allegri et al., 2016)

Dengan mengetahui faktor-faktor ini maka perlu suatu strategi pencegahan terpadu untuk mencegah Low Back Pain. Kegiatan penyuluhan terkait nyeri pinggang belakang atau low back serta cara mengatasinya. Kegiatan ini dilakukan bertujuan untuk memberikan edukasi terkait pengetahuan nyeri pinggang belakang saat aktivitas sebagian besar dirumah, posisi kerja yang baik, gerakan yang dihindari, serta senam yang dapat mengatasi keluhan nyeri pinggang belakang serta diet yang seimbang untuk mencegah LBP. Target dari kegiatan penyuluhan adalah menurunkan angka kejadian nyeri pinggang belakang serta meningkatkan kualitas hidup agar tetap berkarya selama Pandemi. Target kegiatan ini adalah masyarakat dapat bertambah pengetahuan terkait low back pain, meningkatkan derajat kesehatan individu serta mengedukasi agar pola hidup sehat, memperhatikan asupan gizi serta giat berolahraga.

\section{METODE PELAKSANAAN PKM}

Metode yang akan digunakan pada kegiatan bakti kesehatan adalah penyuluhan dan pelatihan. Peserta akan diberikan edukasi mengenai low back pain. Setelah itu peserta diberikan edukasi, peserta akan diberikan pelatihan berupa cara untuk menghindari kemungkinan terjadinya gangguan low back pain dan gangguan muskuloskeletal lainnya akibat bekerja menggunakan laptop yang kelamaan. Calon peserta akan diberikan informasi kegiatan bakti kesehatan ini dengan menyebarkan flyer. Bagi peserta yang ingin mengikuti kegiatan bakti kesehatan ini akan disediakan link untuk melakukan pendaftaran terlebih dahulu. Kegiatan bakti kesehatan akan dilakukan secara daring. Peningkatan pengetahuan peserta mengenai kegiatan bakti kesehatan ini akan dinilai dengan hasil pretes dan postes. Pada kegiatan ini, pretes dan postes dilakukan dengan mengisi google form (gform) yang disediakan oleh tim pengusul. Tautan untuk gform diberikan kepada para peserta sebelum pretes dan postes dilakukan. Materi pretes dan postes berisikan lima buah pertanyaan yang sama terkait dengan materi penyuluhan yang diberikan oleh narasumber. Tujuan diberikan materi pertanyaan yang sama antara pre dan postes adalah untuk melihat tingkat penerimaan materi oleh para peserta pengabdian.

\section{HASIL DAN PEMBAHASAN}

Pandemi global telah membuat sebagian besar beraktivitas di rumah selama berbulan-bulan sekarang, bekerja dari rumah dan dibatasi kegiatan diluar ruangan, hampir semua waktu aktivitas kehidupan di dalam ruangan, kondisi ini menimbulkan tantangan kesehatan yang signifikan. Meningkatnya jumlah jam yang dihabiskan untuk duduk, memiliki postur tubuh yang tidak tepat, kurang olah raga, pola makan yang tidak sehat dan stres pandemi, semuanya dapat menyebabkan nyeri punggung bawah yang berkepanjangan. Berdasarkan survey didapatkan beberapa permasalahan yang dihadapi. Maka dilakukan persiapan yaitu menyiapkan materi kegiatan PKM, melakukan penyuluhan dan tanya jawab. Tim pengabdian membuat kuisioner penilaian dengan memberikan pretest dan posttest, pelaksanaan penyuluhan. Evaluasi dilakukan untuk mengetahui sejauh mana efektivitas program ini untuk mencapai tujuan kegiatan yang telah dicanangkan. Adapun aspek yang dievaluasi meliputi: efektvitas pelaksanaan dilihat dari: manfaat kegiatan, tingkat pengetahuan dan pemahaman terkait materi penyuluhan. Kegiatan penyuluhan pinggang belakang dilakukan via daring pada tanggal 27 Mei 2021 pukul 8.00-12.00, kegiatan dihadiri oleh 
44 peserta yang berasal dari kader PKK Kelurahan Tomang Jakarta Barat. Kegiatan penyuluhan dilakukan pre-test dan pos-test, diberikan pertanyaan sebanyak 5 buah pertanyaan.

\section{Gambar 1}

Alur Pelaksanaan Edukasi Low Back Pain kepada Peserta

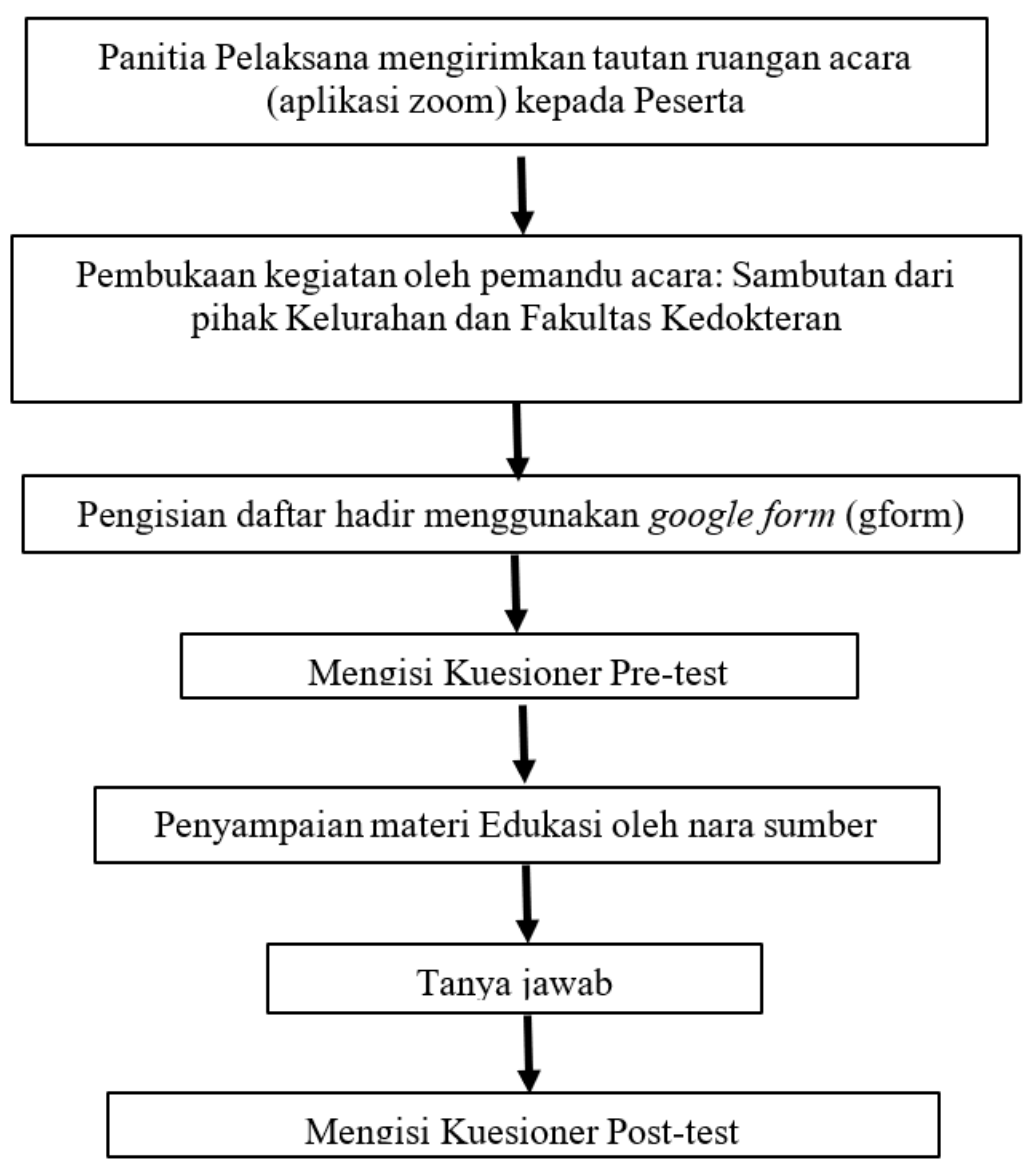

\section{Gambar 2}

Hasil Pengisian Kuesioner Pre dan Post-test

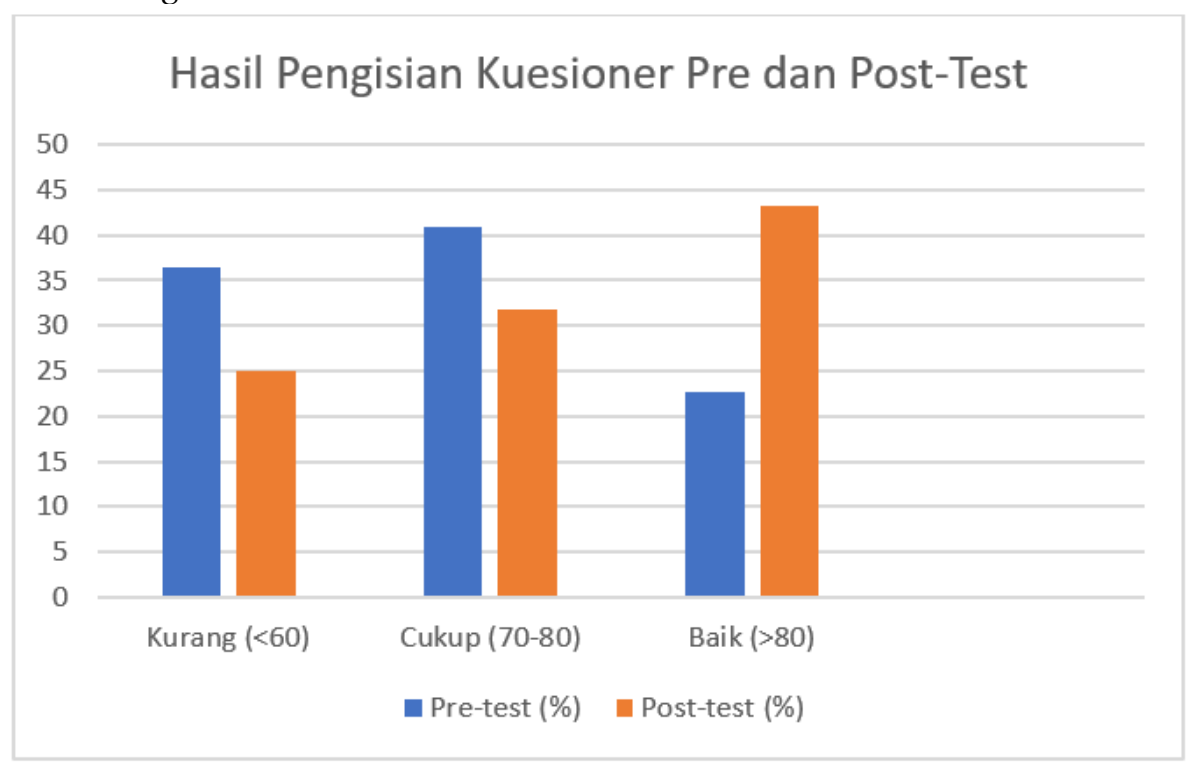


Hasil nilai rata-rata pre-test sebesar 53.63, dan hasil pos-test dengan nilai rata-rata sebesar 62.27. Hasil tersebut menunjukkan masih kurangnya pengetahuan nyeri pinggang belakang dan dengan dilakukan penyuluhan terjadi peningkatan pengetahuan sebesar $16.10 \%$. Penyuluhan terkait pinggang belakang menambah wawasan terkait kesehatan serta pencegahan nyeri pinggang belakang serta melalui kegiatan ini diharapkan peserta dapat menerapkan materi terkait pencegahan nyeri pinggang belakang dengan senam, asupan gizi yang baik dan diharapkan mengedukasi keluarganya dan masyarakat tentang kebiasaan dalam mencegah nyeri pinggang belakang.

\section{KESIMPULAN DAN SARAN}

Penyuluhan terkait informasi tentang pencegahan kejadian low back pain selama bekerja menggunakan komputer merupakan upaya untuk menambah pengetahuan dalam bidang kesehatan terutama sangat dibutuhkan pada masa pandemi ini. Hal ini dikarenakan banyak kegiatan yang yang beralih menjadi dikerjakan di rumah, seperti work from home atau school from home.

\section{Ucapan Terima Kasih (Acknowledgement)}

Pada kesempatan ini, tim ingin menyampaikan ucapan terima kasih kepada Lembaga Penelitian dan Pengabdian kepada Masyarkat atas pendanaan dalam kegiatan ini. Terima kasih juga disampaikan kepada seluruh peserta yang telah mengikuti kegiatan bakti kesehatan ini, sehingga kegiatan dapat terlaksana dengan baik dan lancer. Terima kasih juga kepada Panitia Serina yang sudah memberikan kesempatan untuk berpatisipasi pada kegiatan SERINA 2021

\section{REFERENSI}

Alhalabi, M. S., Alhaleeb, H. \& Madani, S. (2015) Risk factors associated with chronic low back pain in Syria. Avicenna Journal of Medicine, 5(4), 110-116. https://www.ncbi.nlm.nih.gov/pmc/articles/PMC4637947/

Allegri, M., Montella, S. \& Salici, F. (2016). Mechanisms of low back pain: A guide for diagnosis and therapy [version 2; referees: 3 approved]. Flo00Research, 5, 1-11. https://pubmed.ncbi.nlm.nih.gov/27408698/

Almoallim, H., Alwafi, S. \& Albazli, K. (2014). A Simple approach of low back pain. International Journal of Clinical Medicine, 5, 1087-1098. https://www.scirp.org/journal/PaperInforCitation.aspx?PaperID=49767

Brady, S. R. E., Hussain, S. M., Brown, W. J., Heritier, S., Billah, B., Wang, Y., Teede, H., Urquhart, D. M. \& Cicuttini, F. M. (2016). Relationships between weight, physical activity, and back pain in young adult women. Medicine (Baltimore), 95. https://pubmed.ncbi.nlm.nih.gov/27175634/

Bento, T. P. F., Genebra, C. V. D. S., Maciel, N. M., Cornelio, G. P., Simeão, S. F., de Vitta, A. (2020). Low back pain and some associated factors: Is there any difference between genders? Brazilian J. Phys. Ther., 24, 79-87. https://www.mdpi.com/1660-4601/17/19/7302/htm

Crow, W. T. \& Willis, D. R. (2009). Estimating cost of care for patients with acute low back pain: A retrospective review of patient records. J. Am. Osteopath. Assoc., 109, 229-233. https://pubmed.ncbi.nlm.nih.gov/19369510/

Coenen, P. (2013). On the origin of back pain. VU University Amsterdam. https://www.researchgate.net/publication/260612688_On_the_origin_of_back_pain

Dutmer, A. L., Preuper, H. R. S., Soer, R., Brouwer, S., Bültmann, U., Dijkstra, P. U., Coppes, M. H., Stegeman, P., Buskens, E., van Asselt, A. D. I., Wolff, A. P., Reneman, M. F. (15 Desember 2019). Personal and societal impact of low back pain: the groningen spine cohort. Spine, 44(24), 1443-1451. https://pubmed.ncbi.nlm.nih.gov/31369481/ 
Emel, Y. \& Ozden, D. (2012). Effect of physical and psychosocial factors on occupational low back pain. Health Science Journal. 6(4), 598-609. https://www.researchgate.net/publication/288583724_Effect_of_physical_and_psychosoci al_factors_on_occupational_low_back_pain

Fatoye, F., Gebrye, T. \& Odeyemi, I. (2019). Real-world incidence and prevalence of low back pain using routinely collected data. Rheumatol. Int., 39, 619-626. https://pubmed.ncbi.nlm.nih.gov/30848349/

Gallagher, S. (2008). Reducing low back pain and disability in mining. National Institute for Occupational Safety and Health (NIOSH). https://www.cdc.gov/ niosh/mining/UserFiles/works/pdfs/2008-135.pdf

Huang, C., Wang, Y., Li, X., Ren, L., Zhao, J., Hu, Y., Zhang, L., Fan, G., Xu, J., Gu, X., et al. Clinical features of patients infected with 2019 novel coronavirus in Wuhan, China. Lancet 2020, 395, 497-506. https://www.thelancet.com/pdfs/journals/lancet/PIIS0140$6736 \% 2820 \% 2930183-5 . p d f$

James, S. L., Abate, D., Abate, K. H., Abay, S. M., Abbafati, C., Abbasi, N., Abbastabar, H., AbdAllah, F., Abdela, J., Abdelalim, A., et al. (10 November 2018). Global, regional, and national incidence, prevalence, and years lived with disability for 354 diseases and injuries for 195 countries and territories, 1990-2017: A systematic analysis for the Global Burden of Disease Study 2017. Lancet, 392, 1789-1858. https://pubmed.ncbi.nlm.nih.gov/30496104/

Lionel, K. A. (2014). Risk factors for chronic low back pain. Journal Community Medicine and Health Education, 4(2), 1-4. https://www.researchgate.net/publication/270010652_Risk_ Factors_Forchronic_Low_Back_Pain

Mattioli, A.V., Puviani, M. B., Nasi, M., Farinetti, A. (2020). Covid-19 pandemic: The effects of quarantine on cardiovascular risk. Eur. J. Clin. Nutr., 74, 852-855. https://pubmed.ncbi.nlm.nih.gov/32371988/

Meisha, D. E., Alsharqawi, N. S., Samarah, A. A., Al-Ghamdi, M. Y. (2019). Prevalence of workrelated musculoskeletal disorders and ergonomic practice among dentists in Jeddah, Saudi Arabia. Clin. Cosmet. Investig. Dent., 11, 171-179. https://pubmed.ncbi.nlm.nih.gov/ $31308760 /$

Minghelli, B. (2017). Low back pain in childhood and adolescent phase: consequences, prevalence dan risk factors - a revision. Journal of Spine, 6(1), 1-6. https://www.hilarispublisher.com/ open-access/low-back-pain-in-childhood-and-adolescence-phase-consequencesprevalence-and-risk-factors--a-revision-2165-7939-1000351.pdf

Simsek, S. (2017). Prevalence and risk factors of low back pain among health-care workers in denizli. Agrl - J. Turkish Soc. Algol., 29, 71-78. https://pubmed.ncbi.nlm.nih.gov/28895982/

Wilder-Smith, A., Freedman, D. O. (2020). Isolation, quarantine, social distancing and community containment: Pivotal role for old-style public health measures in the novel coronavirus (2019-nCoV) outbreak. J. Travel Med., 27. https://pubmed.ncbi.nlm.nih.gov/32052841/ 